\title{
COVID-2019 and Its Shadow on Gastrointestinal Endoscopy
}

\author{
T. S. Chandrasekar ${ }^{1}$ Raja Yogesh Kalamegam \\ ${ }^{1}$ Department of Gastroenterology, Medindia Hospitals, \\ Chennai, India
}

J Digest Endosc 2020;11:31-32

The ongoing COVID 19 pandemic has already taken a brutal toll on humanity. What started as pneumonia of unknown origin in a small pocket in China in December 2019 has now grown to gargantuan proportions to threaten every field known to mankind. The financial and more importantly, the impact in terms of the number of lives lost is unprecedented in recent times. With the number of cases and fatalities increasing exponentially by the day, the pandemic has given little time to brace ourselves against the impact. With the sheer volume of newly diagnosed cases, it has thrown the health and medical infrastructure of most countries into a state of disarray. The extent of havoc is still unfathomable, given that the infection count is still on the rise in most countries.

Being a "novel" virus, our understanding on several aspects of the virus is incomplete or rather still in evolution. What has been firmly established though is its high degree of infectivity. The rate of increase in the number of cases with each passing day by itself bears testimony to the infective potential. The primary modes of transmission are through direct contact, respiratory droplets, and fomites. This fact understandably would set the alarm bells ringing for the practicing endoscopist, since endoscopy as a procedure would potentially entail all these three modes of transmission.

It has been established that the severe acute respiratory syndrome coronavirus 2 (SARS-CoV-2) virus gains entry into cells by attachment to the ACE2 receptor protein. ${ }^{1}$ Studies by Zhang et al on single-cell transcriptomes have shown this receptor protein to be present not only in the lungs but in the gastrointestinal epithelial cells as well. ${ }^{2}$ This makes the gastrointestinal (GI) tract a potential route of transmission of the virus. Viral RNA has been detected in stools in nearly $54 \%$ of COVID-19 patients. ${ }^{3}$ What is alarming is that this fecal shedding of the viral RNA can continue even after the patient has recovered from the respiratory symptoms. ${ }^{4}$ There have also been reports of electron microscopy demonstrating the live virus in stool specimens. These facts highlight the possibility of the GI tract being a potential route of transmission,
Address for correspondence T. S. Chandrasekar, MD, DM, DSc, MWGO, FRCP, FACG, Department of Gastroenterology, Medindia Hospitals, Chennai 600034, India (e-mail: tscmedindia@gmail.com).

worryingly even from asymptomatic patients. Though there has not been any documentation of feco-oral transmission of SARS-CoV-2 till date, it would be imprudent to disregard the possibility.

In the context of physical distancing, which is conceivably our best strategy to delink the chain of transmission, the endoscopic suite that we are most accustomed to represent a scene that is perhaps the antithesis of physical distancing. Several endoscopy personnel, namely the endoscopist, the endoscopy assistant, the endoscopy nurse, the anesthetist, the helpers, the patient, and sometimes even his overanxious attendant, within a relatively confined space may potentially serve as a hot-bed for the spread of infection. The steady flux of personnel also aggravates the likelihood of infection transmission. Though the endoscopy suite should ideally be a negative pressure room to minimize the chance of infection spread, presently there are but a few endoscopy centers which would meet the exact standards.

Endoscopic procedures intrinsically, places us in close proximity to the patent's aero-digestive tract, making it a procedure with a high risk of transmission to the endoscopist. It is well established that endoscopy is an aerosol-generating procedure. During endoscopy, particularly during the time of intubation, there is a high likelihood of eliciting the cough and gag reflex, thereby increasing the dissemination of aerosols from the aero-digestive tract. The act of suctioning may also generate aerosols. The possibility of physical contact with patient's salivary, respiratory, and digestive secretions directly as well as indirectly through the endoscope and its accessories, should be borne in mind. The surfaces in the close vicinity of the procedure onto which the infective droplets may be deposited may also act as fomites serving as a potential route of transmission.

Apart from the perils of transmission of infection to endoscopy personnel, the risk of SARS-CoV-2 transmission from patient to patient must also be considered. Proper reprocessing of endoscopes and accessories must be stressed 
in this context. Thankfully, standard chemical solutions and techniques recommended for endoscope reprocessing appear to be helpful against SARS-CoV-2 as well.

In the article published in the present edition, the author Dr. Surinder Rana discusses lucidly the characteristics of SARS-CoV-2 virus, the clinical features of COVID 19, the modes of transmission, and the high infectivity of the virus. ${ }^{5}$ The risk of transmission in the setting of gastrointestinal endoscopy is reviewed in great detail. In the present circumstances, the article also serves as a sound prelude to the other pertinent topics discussed in this edition, such as triaging patients based on risk, and the appropriate PPE recommendations for endoscopy.

Recalling the inherent risks of transmission, compels us, as endoscopist to be vigilant, well prepared and perhaps also well armored in the combat against infection transmission. In this great war, we owe this as a responsibility to ourselves, our patients, and also our society at large.

\section{References}

1 Hoffmann M, Kleine-Weber H, Krüger N, Müller M, Drosten C, Pöhlmann, S. The novel coronavirus 2019 (2019-nCoV) uses the SARS-coronavirus receptor ACE2 and the cellular protease TMPRSS2 for entry into target cells. bioRxiv 2020;/2020.01.31.929042

2 Zhang $\mathrm{H}$, Kang $\mathrm{Z}$, Gong $\mathrm{H}$, et al. The digestive system is a potential route of 2019-nCov infection: a bioinformatics analysis based on single-cell transcriptomes. bioRxiv 2020;/2020.01.30.927806

3 Xiao T, Zheng L, Li S, Evidence for gastrointestinal infection of SARS-CoV-2. gastroenterology, 2020; Mar 3. pii: S0016-5085(20)30282-1 https://doi 10.1053/j.gastro.2020. 02.055

4 Wu Y, Guo C, Tang L, et al. Prolonged presence of SARS-CoV-2 viral RNA in faecal samples. Lancet Gastroenterol Hepatol 2020;5(5):434-435

5 SS Rana. Risk of COVID-19 Transmission During Gastrointestinal Endoscopy. samples. J Digest Endosc 2020;11:27-30 